\title{
Functional-Anatomic Correlates of Sustained and Transient Processing Components Engaged during Controlled Retrieval
}

\author{
Katerina Velanova, ${ }^{1}$ Larry L. Jacoby, ${ }^{1}$ Mark E. Wheeler, ${ }^{1,2}$ Mark P. McAvoy, ${ }^{2}$ Steve E. Petersen, ${ }^{1,2,3,4}$ and \\ Randy L. Buckner ${ }^{1,2,3,5}$ \\ Departments of ${ }^{1}$ Psychology, ${ }^{2}$ Radiology, ${ }^{3}$ Anatomy and Neurobiology, ${ }^{4}$ Neurology, and ${ }^{5}$ Howard Hughes Medical Institute, Washington University, \\ St. Louis, Missouri 63130
}

\begin{abstract}
Controlled processing is central to episodic memory retrieval. In the present study, neural correlates of sustained, as well as transient, processing components were explored during controlled retrieval using a mixed blocked event-related functional magnetic resonance imaging paradigm. Results from 29 participants suggest that certain regions in prefrontal cortex, including anterior left inferior prefrontal cortex near Brodmann's Area (BA) 45/47 and more posterior and dorsal left prefrontal cortex near BA 44, increase activity on a trial-by-trial basis when high levels of control are required during retrieval. Providing direct evidence for control processes that participate on an ongoing basis, right frontal-polar cortex was strongly associated with a sustained temporal profile during high control retrieval conditions, as were several additional posterior regions, including those within left parietal cortex. These results provide evidence for functional dissociation within prefrontal cortex. Frontal-polar regions near BA 10 associate with temporally extended control processes that may underlie an attentional set, or retrieval mode, during controlled retrieval, whereas more posterior prefrontal regions associate with individual retrieval attempts. In particular, right frontal-polar cortex involvement in sustained processes reconciles a number of disparate findings that have arisen when contrasting blocked-trial paradigms with event-related paradigms.
\end{abstract}

Key words: memory; neuroimaging; retrieval; recognition; control; fMRI; retrieval mode; attention; prefrontal; parietal

\section{Introduction}

Controlled processing is central to intentional memory retrieval. Defined broadly, controlled processing reflects a person's intentions, is subject to capacity limitations, and tends to operate in situations in which task goals cannot be achieved through automated stimulus-response mappings (Schneider and Shiffrin, 1977). The need for controlled processing in memory arises because the amount of information stored in memory exceeds the specific information that is required at any given moment (Tulving and Pearlstone, 1966). Cognitive theories of episodic retrieval often ally controlled retrieval processing with the recollection of contextual details surrounding a previous encounter with a stimulus and contrast recollection with a less controlled familiarity process (Mandler, 1980; Jacoby, 1991; Yonelinas, 2002). In the present study, we explored neural correlates of controlled processing components engaged during recognition tasks specifically designed to differentially encourage highly controlled or less controlled retrieval decisions. Following current theories of at-

Received May 7, 2003; revised July 31, 2003; accepted July 31, 2003.

This research was supported by the Howard Hughes Medical Institute, the James S. McDonnell Foundation, and the National Institute of Mental Health (MH57506). We thank Fran Miezin, Abraham Snyder, Erbil Akbudak, and Tom Conturo for support and development of the MRI procedures. Erica Palmer and Kristina Visscher provided invaluable assistance with data analysis. We also thank Mick Rugg and David Donaldson for helpful discussion.

Correspondence should be addressed to Randy L. Buckner, Washington University in St. Louis, Department of Psychology, One Brookings Drive, Campus Box 1125, St. Louis, M0 63130. E-mail: rbuckner@artsci.wustl.edu.

Copyright $\odot 2003$ Society for Neuroscience $\quad 0270-6474 / 03 / 238460-11 \$ 15.00 / 0$ tention (Desimone and Duncan, 1995; Bundeson, 1999), where possible we distinguish between "control processes" (the source of top-down control) and "controlled processes" (the site of control).

During any retrieval task, both control processes and controlled processes may operate on a trial-by-trial basis (as, for example, when a person initiates a retrieval attempt) and also in a sustained manner [as when a person adopts a "retrieval mode" (Tulving, 1983; Nyberg et al., 1995; Düzel et al., 1999; Rugg and Wilding, 2000)]. The goal of the present study was to identify neural correlates of sustained and transient, or trial-related, controlled processing components. Here, differing levels of control were induced by manipulating conditions at encoding, before a scanned recognition task. Specifically, participants studied one list of words repeatedly (20 times) under intentional instructions and practiced retrieval multiple times before scanning. A second list of words was studied once under deep encoding conditions. The first condition encouraged participants to rely on minimal controlled processing to distinguish between well rehearsed (repeatedly studied) targets and new lures. In contrast, the second study condition encouraged participants to recollect, using a high level of controlled processing, the episodic details of an item's previous occurrence to distinguish between once-presented (deeply encoded) targets and new lures.

This behavioral manipulation, which yielded low control and high control retrieval conditions, was combined with recently 
developed event-related functional magnetic resonance imaging (fMRI) procedures that can separate transient responses to individual trials from those associated with sustained changes adopted in specific task contexts (Chawla et al., 1999; Donaldson and Buckner, 2001; Donaldson et al., 2001; Otten et al., 2002; Visscher et al., 2003a). In this manner, functional anatomy associated with changes in controlled processing that occur on a trialby-trial basis were explored as well as changes instantiated on an ongoing basis to enable a retrieval mode, or cognitive set, during epochs of controlled remembering (Tulving, 1983; Nyberg et al., 1995; Düzel et al., 1999; Rugg and Wilding, 2000).

To date, sustained and trial-related processes have been difficult to dissociate using neuroimaging techniques. Standard event-related procedures examine trial-related activity in isolation, whereas blocked procedures confound sustained and trialrelated processes by averaging over extended epochs that include all forms of ongoing activity. In contrast, this study reveals that certain brain regions show dissociable patterns of sustained and trial-related activity and, perhaps most significantly, that right frontal-polar contributions to memory retrieval can be strongly associated with sustained, mode-related control processes.

\section{Materials and Methods}

Participants

Thirty-four participants from the Washington University community volunteered and received $\$ 25$ per hour as payment. All were native English speakers with normal or corrected to normal vision and reported no history of neurological problems. Five participants were either unable to complete the study or produced data with sufficient artifacts to preclude further analysis. Thus, fMRI data from 29 participants are reported (18 females, 11 males, mean age 21.3 years, range $18-31$ years). Behavioral data for pre-scan and post-scan lure recognition tests for one participant were lost because of equipment failure. Informed consent was obtained from all participants in accordance with the guidelines and approval of the Washington University Human Studies Committee.

\section{Data acquisition}

MRI data were acquired using a Siemens 1.5 Tesla Vision System (Erlangen, Germany) with a standard circularity-polarized head coil. Pillows and thermoplastic face masks minimized head movement. Headphones dampened scanner noise and allowed communication with participants. A power Macintosh computer (Apple, Cupertino, CA) and PsyScope software (Cohen et al., 1993) controlled stimulus display and recorded responses from a magnet-compatible fiber-optic key-press device. An LCD projector (Epson 500C LCD, Sharp LCD PG-C20XU) projected stimuli onto a screen at the head of the bore, viewable via a mirror attached to the head coil.

Structural images were acquired first, using a sagittal MP-RAGE T1weighted sequence $[$ repetition time $(\mathrm{TR})=9.7 \mathrm{msec}$; echo time $(\mathrm{TE})=$ $4 \mathrm{msec}$; flip angle $a=10^{\circ}$; inversion time (TI) $=20 \mathrm{msec}$; voxel size $=$ $1 \times 1 \times 1.25 \mathrm{~mm}]$. Functional images were acquired using an asymmetric spin-echo echo-planar sequence (Conturo et al., 1996) sensitive to blood oxygenation level-dependent $(\mathrm{BOLD})$ contrast $\left(\mathrm{T} 2^{\star}\right)(\mathrm{TR}=2.36$ sec; $\mathrm{TE}=37 \mathrm{msec}$; flip angle $=90^{\circ}$; voxel size $=3.75 \times 3.75 \mathrm{~mm}$ in-plane resolution). Participants performed four functional runs (before performance of an additional experiment, reported separately) during which 128 sets of 16 contiguous 8 -mm-thick axial images were acquired parallel to the anterior commissure-posterior commissure plane. Functional runs began with four "dummy" image acquisitions to allow stabilization of longitudinal magnetization.

\section{Behavioral paradigm}

The experiment was conducted over $2 \mathrm{~d}$, with scanning occurring on day 2. On day 1, participants sat in front of a computer monitor and studied words presented via a Power Macintosh computer, making key presses on a PsyScope Button Box (Cohen et al., 1993). Participants studied and were tested repeatedly on one set of 60 words during each of three study blocks. During these blocks the same set of 60 words was presented five times. Words were presented [ $1 \mathrm{sec}$ duration, $0.5 \mathrm{sec}$ interstimulus interval (ISI) of fixation] in random order with the restriction that at least one item intervene between repetitions. Participants were instructed to read words aloud and to remember them for a later memory test.

Each study block was followed immediately by a recognition test. During these tests, the 60 words presented for study were randomly intermixed with 60 new lures (that differed for each test) and 60 fixation trials. Test stimuli were presented for $1.5 \mathrm{sec}$ duration ( $0.86 \mathrm{sec}$ ISI of fixation). Participants responded "old" or "new" using the index fingers of each hand (with hand counterbalanced across participants, resulting in 13 participants using their right hand for old). Participants were instructed to make old-new judgments quickly and accurately. This study test procedure was repeated three times such that on day 1 participants studied each of the 60 target words 15 times. Participants thus became well practiced at making recognition decisions for these critical words.

On day 2, before scanning, participants performed one more study session (as above), intended to refresh their memory for the targets presented on day 1 . This concluded the (intentional) encoding procedure for words to be presented in "low control" retrieval scans. Immediately after this study session, participants performed a pleasantness judgment task in which 60 words (not presented elsewhere in the experiment) were presented once each. These words became those to be presented in "high control" retrieval scans. Each word was presented for $1 \mathrm{sec}$, followed by an ISI of fixation of varying duration. Participants read each word aloud and then made a pleasantness judgment by stating aloud "pleasant" or "unpleasant." The experimenter keyed in participants' judgments, thus initiating the next trial.

After this (incidental) deep encoding task, participants were brought to the scanner (a delay of $\sim 10-15 \mathrm{~min}$ ) where after acquisition of structural images they performed a recognition memory task requiring discrimination between old target words (presented in the encoding sessions) and new lures (not seen elsewhere in the experiment) during four functional runs. Across runs, the nature of old target words was manipulated. For two consecutive runs (low control retrieval runs), target words were those that had been studied repeatedly using intentional encoding and repeated tests. For the other two runs (high control retrieval runs), target words were those presented in the deep encoding task. Conditions were blocked within runs to maximize the likelihood that participants would maintain task set. Participants were explicitly informed about the source of the old words to be tested before each run. The order of low control and high control retrieval runs was counterbalanced across participants.

Each functional run lasted $\sim 5 \min$ (128 acquisitions, 1 acquisition every $2.36 \mathrm{sec}$ ) separated by a $3 \mathrm{~min}$ break. As Figure 1 shows, during each run participants alternated between blocked periods of the recognition task and blocked periods of fixation. Within the task blocks, trials were temporally jittered to allow transient and sustained signal components to be separated (Chawla et al., 1999; Donaldson et al., 2001). Each block period began with a visual prompt, either "FIXATE!" or “OLD?" (2.36 sec duration). Each fixation block lasted $23.6 \mathrm{sec}$, during which a fixation cross-hair was displayed continuously. Each recognition block lasted for $106.2 \mathrm{sec}$ during which stimuli were presented ( 15 old word trials, 15 new word trials, 15 fixation trials). Test items presented during the recognition task were jittered by interspersing gaps (i.e., fixation trials) throughout the recognition blocks. The presentation of test items was timelocked to the onset of successive whole-brain image acquisitions. Trial order within each recognition block was pseudorandomized so that each type of event (presentation of targets, lures, and fixations) was equally likely to follow the other using procedures described in Miezin et al. (2000).

After the four functional runs relevant to this experiment, an additional four functional runs were acquired as part of a second unrelated experiment. At the completion of scanning, participants returned to the laboratory for a surprise lure recognition task [adapted from Buckner et al. (2001)]. Lure recognition was used as a measure sensitive to the controlled processing mode adopted during the scanned retrieval tasks. During this task, 240 words were presented at participant controlled durations, each followed by a $0.5 \mathrm{sec}$ ISI of fixation. These words comprised the 60 lures presented in low control retrieval runs, the 60 lures presented 


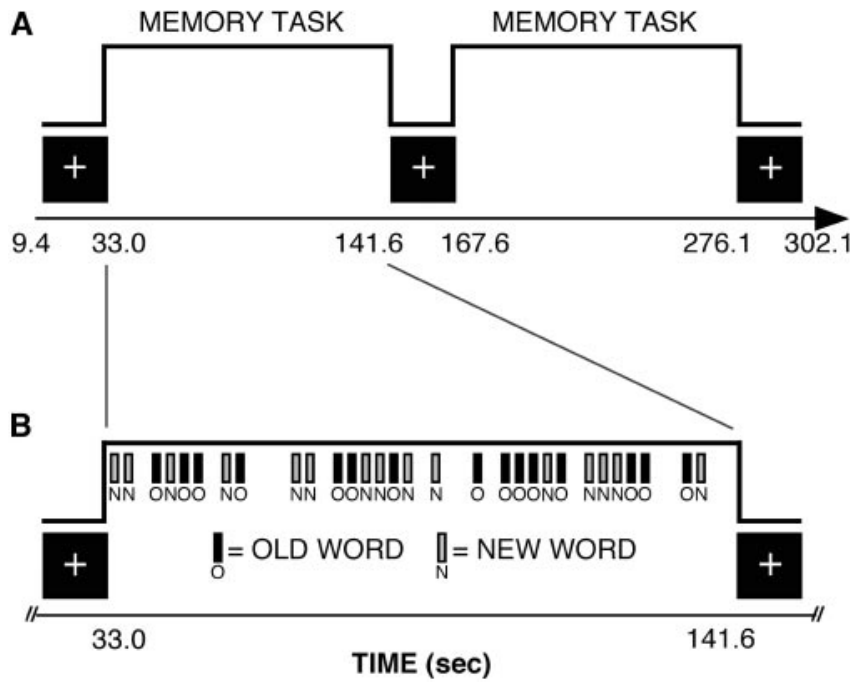

Figure 1. Schematic of the "mixed blocked event-related" design used during a single fMRI run. $A$, In the mixed design, as in a blocked design, each functional run was blocked such that participants alternated between fixation baseline and performing a recognition memory task. $B$, Within each memory block, participants were presented with temporally jittered test items, as in an event-related design (see Materials and Methods).

in high control retrieval runs, and 120 new words (not presented elsewhere in the experiment). Participants identified lures presented previously in the scanner by pressing keys corresponding to "definitely old" (dark red), "probably old" (red), "probably new" (green), and "definitely new" responses (dark green). (Note that in this task old words were items to which participants should have responded new in the scanned recognition task.) Participants were able to refer to a response legend presented at the bottom of the computer screen throughout the task.

Word stimuli consisted of 540 nouns (range, 3-10 letters long; mean frequency, 12 per million; range, 5-25 per million) selected from the Kucera and Francis (1967) norms. These words were subdivided into nine lists of 60 words with lists matched for word length and frequency. Mapping of lists to encoding condition (low control and high control) and item type (targets and lures) was counterbalanced across participants. Stimuli were presented in central vision, in white capital letters on a black background, and subtended $\sim 0.5^{\circ}$ of visual angle per letter.

A caveat regarding our behavioral methods is that level of control was not manipulated independently of encoding task. It is likely that the differing encoding tasks used to yield the high and low control conditions served to influence the type and amount of information that participants subsequently retrieved during the scanned portion of the experiment. Readers may wish to acknowledge this aspect of the design as results from the experiment are reported.

\section{fMRI data analysis}

Imaging data from each participant were preprocessed to remove noise and artifacts. Motion was corrected within and across runs using a rigidbody rotation and translation algorithm (Friston et al., 1996; Snyder, 1996). Image slices were realigned in time to the midpoint of the first slice (using sinc interpolation) to account for differences in acquisition timing across slices. Data were then resampled into a standardized atlas space (Talairach and Tournoux, 1988) using $2 \mathrm{~mm}$ isotropic voxels [see Maccotta et al. (2001) for details of the warping method] and smoothed with a Gaussian spatial filter ( $2 \mathrm{~mm}$ full-width half-maximum). Preprocessed data were analyzed using the general linear model (Friston et al., 1995; Worsley and Friston, 1995; Miezin et al., 2000) implemented in an inhouse analysis and display package. Analyses were performed to separate transient and sustained signal changes in addition to coding for the effects of a linear trend (to account for within-run drift) and constant term (to account for run mean) (Donaldson et al., 2001; Visscher et al., 2003a). Effects for all analyses are described in terms of percentage signal change, defined as signal magnitude divided by the mean of the estimated constant terms (one per run).

Transient effects. For each participant, the BOLD response to each trial type (i.e., responses associated with hits, misses, correct rejections, and false alarms in each retrieval condition) was estimated by coding a different regressor (i.e., $\delta$ function) for each of the seven time points (i.e., image acquisitions) immediately after each stimulus onset. Regressors were also coded to account for the visual prompts at the beginning of each fixation block. This estimation produced one time course estimate (over seven time points per $16.52 \mathrm{sec}$ ) per voxel per trial condition. Separate estimates were computed for trials occurring within the low control and high control blocks. Cross-correlation magnitudes were also computed for each trial condition as the inner product of the estimated time course and a vector of contrast weights modeling the hemodynamic response function. Here, contrast weights were derived from a $\gamma$ function with a delay of $2 \mathrm{sec}$ and time constant of $1.25 \mathrm{sec}$ (Boynton et al., 1996). By definition, the contrast weights summed to zero and were normalized to have a magnitude of 1 . These summary cross-correlation magnitudes from each subject were then entered into a priori analyses using specific regions of interest (see Hypothesis-directed analyses below). The full time course estimates were also entered into exploratory analyses on the basis of ANOVAs that made no regional assumptions (see Exploratory analyses below).

Sustained effects. Two sustained effects, one corresponding to each retrieval condition, were also coded in the general linear model. These effects were coded as occurring across the 46 time points comprising each type of task block (low control and high control). Unlike transient effects, sustained effects were coded as single regressors with an assumed shape (specifically, a $\gamma$ function convolved with a temporally extended boxcar function reaching a maximum value during the task block and zero otherwise) (Boynton et al., 1996). A single magnitude estimate (relative to baseline) for the sustained effect was computed for each condition at each voxel and was entered into $a$ priori analyses using regions of interest (see Hypothesis-directed analyses below). These estimates also entered into exploratory analyses that made no regional assumptions (see Exploratory analyses below).

The temporal profiles of the sustained effects were obtained using the variance that was not explained by the model (i.e., the residual after the effects of fixation prompts, transient item types, linear drift, and run mean were removed). The average residual signal plus the signal associated with the modeled magnitude of a sustained effect was computed for each time point of each participant's data. Estimates of the temporal evolution of the sustained effect were visualized after averaging over all occurrences of the effect for one participant and then averaging across participants.

Hypothesis-directed analyses. On the basis of literature reviews, specific regions of interest associated with controlled retrieval processing were selected a priori from previously published studies from our laboratory (McDermott et al., 1999; Gold and Buckner, 2002; Logan et al., 2002). Additionally, because controlled retrieval is associated with the recovery of episodic information, and consequently with the explicit awareness that information is old, neural correlates of "retrieval success" were also examined. Particular attention was given to parietal and frontal regions that have been associated with the successful recovery of episodic information (Konishi et al., 2000; Wheeler and Buckner, 2003). Regions associated with controlled processing were defined about peak locations at (1) BA 45/47: - 45, 35, -4 (Gold and Buckner, 2002; Logan et al., 2002); (2) BA 44: -47, 17, 24 (Gold and Buckner, 2002); (3) BA 6: $-55,-1,28$ (Gold and Buckner, 2002); and (4) BA 10: 37, 51, 12 (McDermott et al., 1999). Regions associated with retrieval success were centered on (1) BA 40/39: - 39, - 55, 36 (Konishi et al., 2000; Wheeler and Buckner, 2003) and (2) BA 10/46: - 35, 51, 8 (Konishi et al., 2000). Table 1 provides a summary of the regions, their peak locations, and representative publications that have suggested a role in memory retrieval or related controlled processing.

Estimates of the transient and sustained signal changes were averaged across all voxels within each region and were submitted to analyses on the basis of a mixed-effects model, with subjects as a random factor. Analyses were performed to determine whether activity modulated between con- 
Table 1. Regions of interest

\begin{tabular}{|c|c|c|c|c|c|}
\hline \multirow[b]{2}{*}{ Region $^{a}$} & \multirow[b]{2}{*}{ Approximate location } & \multicolumn{3}{|c|}{ Atlas coordinates } & \multirow[b]{2}{*}{ Reference papers ${ }^{b}$} \\
\hline & & $x$ & $y$ & $z$ & \\
\hline BA $45 / 47^{c}$ & Left (anterior) inferior frontal gyrus & -45 & 35 & -4 & $1,2,3,4,5,6,7,8$ \\
\hline BA $44^{c}$ & Left (posterior) inferior frontal gyrus & -47 & 17 & 24 & $4,7,8,9,10$ \\
\hline $\mathrm{BA} 6^{\mathrm{C}}$ & Left precentral gyrus & -55 & -1 & 28 & $4,7,8,9,11$ \\
\hline BA $10^{c}$ & Right frontal-polar cortex & 37 & 51 & 12 & $\begin{array}{c}5,9,12,13,14,15,16 \\
17,18,19,20,21,22 \\
23,24,25,26,27\end{array}$ \\
\hline $\mathrm{BA} 40 / 39^{d}$ & Left lateral parietal cortex & -39 & -55 & 36 & $10,28,29,30,31,32$ \\
\hline $\mathrm{BA} 10 / 46^{d}$ & Left anterior frontal cortex & -35 & 51 & 8 & $6,27,30,31$ \\
\hline
\end{tabular}

a Regions are named on the basis of approximate Brodmann area (BA) in the Talairach and Tournoux (1988) atlas. Region labels should be considered approximate.

${ }^{b}$ Selected reference papers that motivate interest in the regions: (1) Petersen et al., 1989; (2) Raichle et al., 1994; (3) Buckner et al., 1995a; (4) Poldrack et al., 1999; (5) Rugg et al., 1999; (6) Ranganath et al., 2000; (7) Wagner et al., 2001b; (8) Gold and Buckner, 2002; (9) McDermott et al., 1999; (10) Wheeler and Buckner, 2003; (11) Jonides et al., 1998; (12) Squire et al., 1992; (13) Tulving et al., 1994; (14) Buckner et al., 1995b; (15) Nyberg et al., 1995; (16) Buckner et al., 1996; (17) Rugg et al., 1996; (18) Schacter et al., 1997; (19) MacLeod et al., 1998; (20) Buckner et al., 1998b; (21) Rugg et al., 1998; (22) Wagner et al., 1998; (23) Düzel et al., 1999; (24) Düzel et al., 2001; (25) Henson et al., 2000; (26) Lepage et al., 2000; (27) McDermott et al., 2000; (28) Henson et al., 1999a; (29) Henson et al., 1999b; (30) Habib and Lepage, 1999; (31) Konishi et al., 2000; (32) Donaldson et al., 2001.

'Regions predicted to be involved in controlled processing.

${ }^{d}$ Regions predicted to be involved in the perception that information is old during episodic retrieval (or retrieval success).

Table 2. Response accuracies and times for pre-scan tests of recognition for study in the low control condition

\begin{tabular}{llllll}
\hline & \multicolumn{2}{ll}{} & Accuracy $(\mathrm{SE})$ & & \multicolumn{2}{l}{ RT in milliseconds (SE) } \\
\cline { 2 - 3 } \cline { 6 - 7 } & HIT & & & HIT & CR \\
\hline Test 1 & $0.94(0.01)$ & $0.92(0.01)$ & & $744(24)$ & $836(26)$ \\
Test 2 & $0.97(0.01)$ & $0.95(0.02)$ & & $684(21)$ & $757(28)$ \\
Test 3 & $0.97(0.01)$ & $0.97(0.02)$ & & $676(24)$ & $713(27)$ \\
\hline
\end{tabular}

Mean accuracies and response times (RT) with SEMs (SE) in parentheses. CR, Correct rejection.

ditions (low control vs high control) and among trial types (in particular, hits vs correct rejections).

Exploratory analyses. To further explore the data, maps of voxel-wise activity change were constructed in an exploratory manner. For the transient changes, data were analyzed in a three-factor mixed-effects ANOVA with time (having seven levels corresponding to each time point in the estimated trial time courses), retrieval condition (having two levels: low control and high control), and response-based trial classification (two levels; hits and correct rejections) as within-subjects factors (repeated measures). Whole-brain activation maps were generated by converting the $F$ statistics from the ANOVA to $z$ statistics and plotting them across the brain. An advantage of this method is that no hemodynamic response shape is assumed in the ANOVA, and activity in regions showing delayed or atypical responses can be detected (e.g., BA 10) (Schacter et al., 1997; Buckner et al., 1998b). Note, however, that exploratory maps based on ANOVA that are constructed in this manner do not indicate the direction of effects.

To produce whole-brain statistical maps comparing sustained effects with baseline and each other, magnitude estimates were obtained for each participant at each voxel and were similarly submitted to paired $t$ tests. The resulting $t$ statistics were converted to $z$ statistics and were plotted over the whole brain using surface-based representations (Van Essen et al., 2001) [see Wheeler and Buckner (2003) for details of the projection method as applied here].

\section{Results}

The aim of the behavioral procedures was to create two retrieval conditions that differed with respect to the level of control required to perform a recognition task. To this end, before the scanned recognition tests, participants encoded two lists of words in different ways. One list (to be presented in the low control condition) was studied and tested repeatedly (three times). Participants' mean response accuracies and times for these three tests are presented in Table 2. A second list (to be presented in the high control condition) was presented once only but was encoded deeply in a pleasantness judgment task.

Behavioral results from the scanned portion of the experiment suggest that participants adopted two different retrieval sets and that recognition was more controlled in the high control condition. Specifically, participants made less accurate recognition judgments in the high versus low control condition $[p$ (hit) $=$ 0.89 and 0.96 and $p$ (correct rejection) $=$ 0.86 and 0.96 in high and low control runs, respectively] (Fig. $2 A$ ). This was reflected in a $2 \times 2$ (retrieval condition by response) mixed-effects ANOVA by a significant main effect of retrieval condition $\left(F_{(1,28)}=\right.$ 52.44; $p<0.001)$. Response times were also slower in high versus low control condition (912.33 vs $777.12 \mathrm{msec} ; F_{(1,28)}=$ 153.04; $p<0.001)$, with hits being faster than correct rejections $\left(F_{(1,28)}=52.64 ; p<0.001\right)$ (Fig. $2 B$ ). Finally, participants' subsequent memory for lures was better for items presented in the high relative to the low control condition (Fig. $2 C),\left(F_{(1,27)}=27.19 ; p<0.001\right)$. This effect was carried by participants identifying more lures with high confidence in the high control condition $\left(F_{(1,27)}=24.88 ; p<0.001\right)$. Thus our behavioral results suggest that, as intended, participants found retrieval more difficult and more effortful and that they engaged more elaborative retrieval processes, all hallmarks of controlled processing (Schneider and Shiffrin, 1977; Shiffrin and Schneider, 1977; Mandler, 1980; Jacoby, 1991; Koriat, 2000), in the high control condition.

Although lower accuracy and increased response times in the high control condition do not require that a different retrieval set was held, participants' improved memory for critical lures provides strong support for their adopting different retrieval sets across conditions. Moreover, this result is predicted by dualprocess models that identify recollection with meaning and familiarity with appearance and automaticity (Mandler, 1980; Jacoby and Dallas, 1981; Jacoby, 1991).

\section{Hypothesis-directed analyses}

Specific regions of interest associated with differential responding for hits versus correct rejections (or retrieval success) and with controlled retrieval processing were defined $a$ priori, on the basis of literature reviews and recent work in our laboratory (Table 1).

\section{Transient effects}

A frequent finding in the literature is that a left lateral parietal region at or near BA 40/39 and a left anterior frontal region at or near BA 10/46 increase activity when items are retrieved correctly (Habib and Lepage, 1999; Henson et al., 1999b; Konishi et al., 2000; McDermott et al., 2000; Donaldson et al., 2001; Wheeler and Buckner, 2003). Regional analyses in the present study replicated this basic finding and further demonstrated that this modulation to old information can occur within epochs (blocks) that rely on minimally controlled as well as extensively controlled retrieval processes (Fig. 3).

BOLD responses in left lateral parietal cortex (Fig. 3B) were increased significantly for hits relative to correct rejections, reflected in a main effect of response $\left(F_{(1,28)}=47.48 ; p<0.001\right)$ 
when signal magnitude was assessed. Results from ANOVAs assessing magnitudes indicated that there was also a significant response $\times$ retrieval condition interaction $\left(F_{(1,28)}=5.43 ; p<0.05\right)$ with high control hits associated with greater activation than low control hits; however, the interaction of response $\times$ retrieval condition $\times$ time failed to reach significance $\left(F_{(6,168)}=1.39\right.$; $p>0.2)$ when time courses were examined in an analogous analysis. Note however, that qualitatively there was somewhat greater activation for high control hits relative to low control hits.

Transient effects in left anterior frontal cortex (Fig. 3E) followed a similar although not identical pattern. Again, eventrelated BOLD responses increased for hits relative to correct rejections, reflected in a main effect of response $\left(F_{(1,28)}=19.61\right.$; $p<0.001$ ), when signal magnitude was assessed. There was no effect of retrieval condition, nor did any significant interactions (on the basis of magnitudes or time courses) involve level of control.

A second set of analyses focused on regions associated with controlled retrieval (Fig. 4). A region in anterior left inferior prefrontal cortex (aLIPC) near BA 45/47 is frequently reported to be active during semantic (meaning based) word generation and monitoring, and other tasks requiring controlled retrieval processing (Petersen et al., 1989; Raichle et al., 1994; Demb et al., 1995; Roskies et al., 2001; Wagner et al., 2001b; Gold and Buckner, 2002). On the basis of these findings, it has been suggested that BA $45 / 47$ is important in the controlled retrieval of information, in particular, semantic information (Demb et al., 1995; Gabrieli et al., 1998; Wagner et al., 2000; Roskies et al., 2001; Gold and Buckner, 2002) or selection from among competing semantic representations (Thompson-Schill et al., 1997). Consistent with these characterizations, in this study, BA 45/47 (Fig. $4 A-C$ ) showed significantly greater activation in the high control relative to the low control condition regardless of whether participants were responding to studied targets or new lures (i.e., with hits or correct rejections) $\left(F_{(1,28)}=7.65\right.$; $p<0.01$ ).

A second, more posterior portion of left frontal cortex along the dorsal extent of inferior frontal gyrus (pLIPC) at or near BA 44 (Fig. $4 D$ ) was also examined on the basis of previous findings that similar regions modulate in a manner similar to aLIPC (near BA 45/47) (Buckner et al., 1998a; Nolde et al., 1998a,b; Rugg et al., 1999; Ranganath et al., 2000; Wagner et al., 2001a; Gold and Buckner, 2002). In the present experiment, BA 44 modulated with level of control, showing significantly greater activation in the high control condition relative to the low control condition $\left(F_{(1,28)}=25.49 ; p<0.001\right)$ (Fig. $\left.4 E, F\right)$ but no
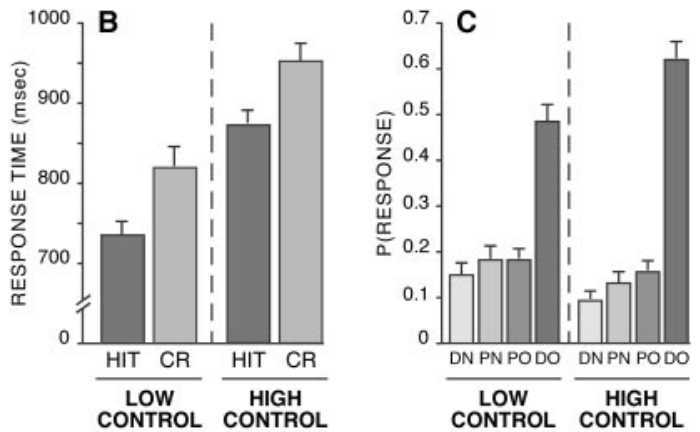

Figure 2. Behavioral results indicate that participants adopted different retrieval sets for the high and low control conditions. $A$, Recognition was less accurate in the high versus low control condition. $B$, Response times were slower in high versus low control conditions, with hits (HIT) being faster than correct rejections (CR). C, Subsequent memory for lures presented during the scanned tests was better for items presented in the high versus low control condition. (In C, DN, PN, PO, and D0 refer to participants identifying critical lures as "definitely new," "probably new," "probably old," and "definitely old.")
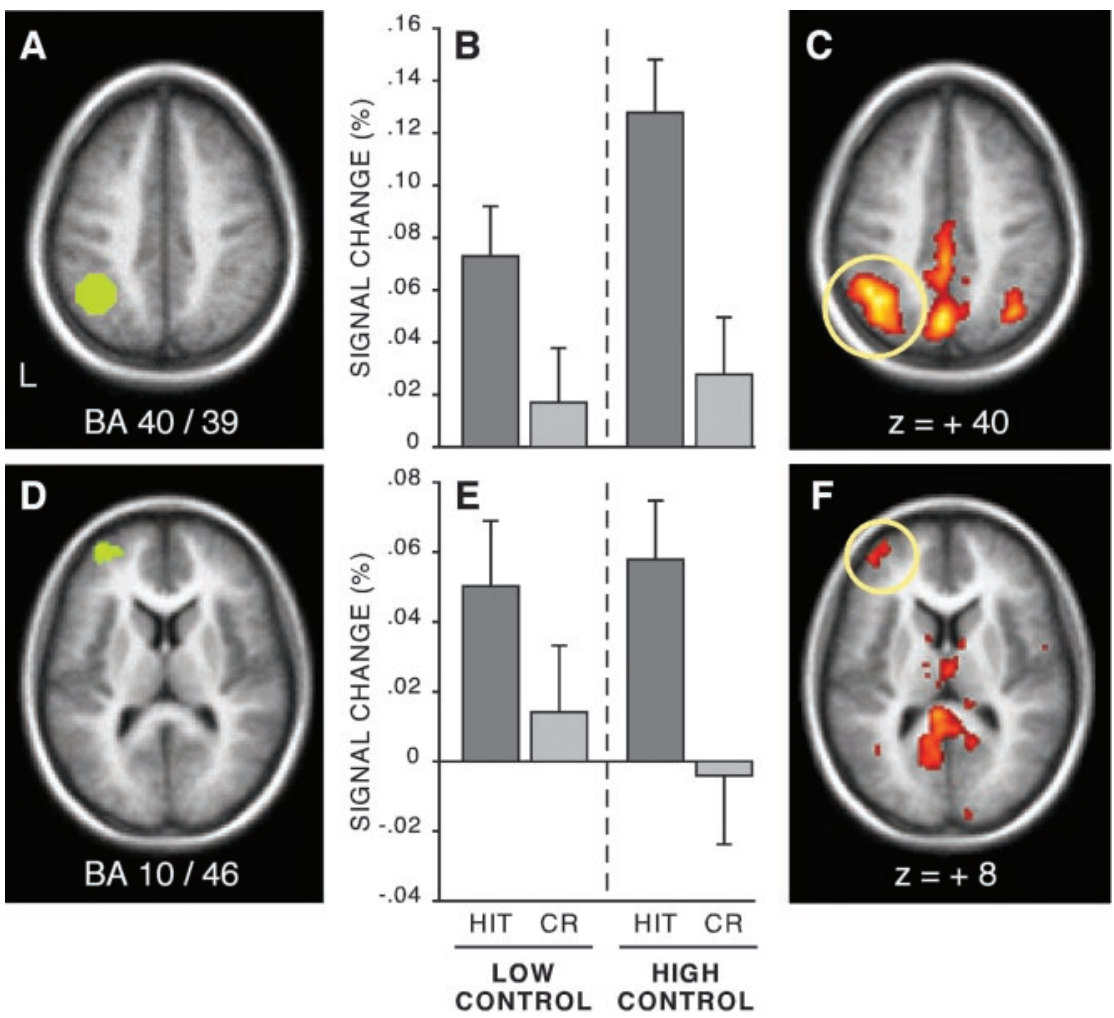

Figure 3. Left parietal and left anterior frontal cortex increased activity for HIT trials versus correct rejection (CR) trials. $A, A$ horizontal section shows the $B A 40 / 39$ region overlaid onto a standardized anatomical image $(z=+40)$. $B$, Magnitude estimates of signal change in BA 40/39 for each condition. A significant HIT/CR difference was obtained in both control conditions. C, A horizontal section showing greater statistical activation at $z=+40$ for HIT trials than for CR trials in exploratory analyses. Thresholds are set at $z=3.29, p=0.001$, two tailed. $D-F$ are similar in layout to $A-C$, respectively, except that the displayed region represents left anterior frontal cortex $(z=+8)$.

significant effect of response $\left(F_{(1,28)}=0.35 ; p>0.5\right)$ or any significant interactions involving retrieval condition and response $\left(F_{(1,28)}=1.99 ; p>0.17\right)$ as would be expected if activity modulated purely with response time, because hits were significantly faster than correct rejections in both retrieval conditions (Fig. 2B).

It is important to note that many previous studies examining activation in pLIPC have frequently focused on large regions that encompass portions of both BA 44 and adjacent BA 6 (Buckner et al., 1998b). Recent work (Dobbins et al., 2002; Gold and Buckner, 2002; McDermott et al., 2003) suggests that BA 44 and BA 6 are 

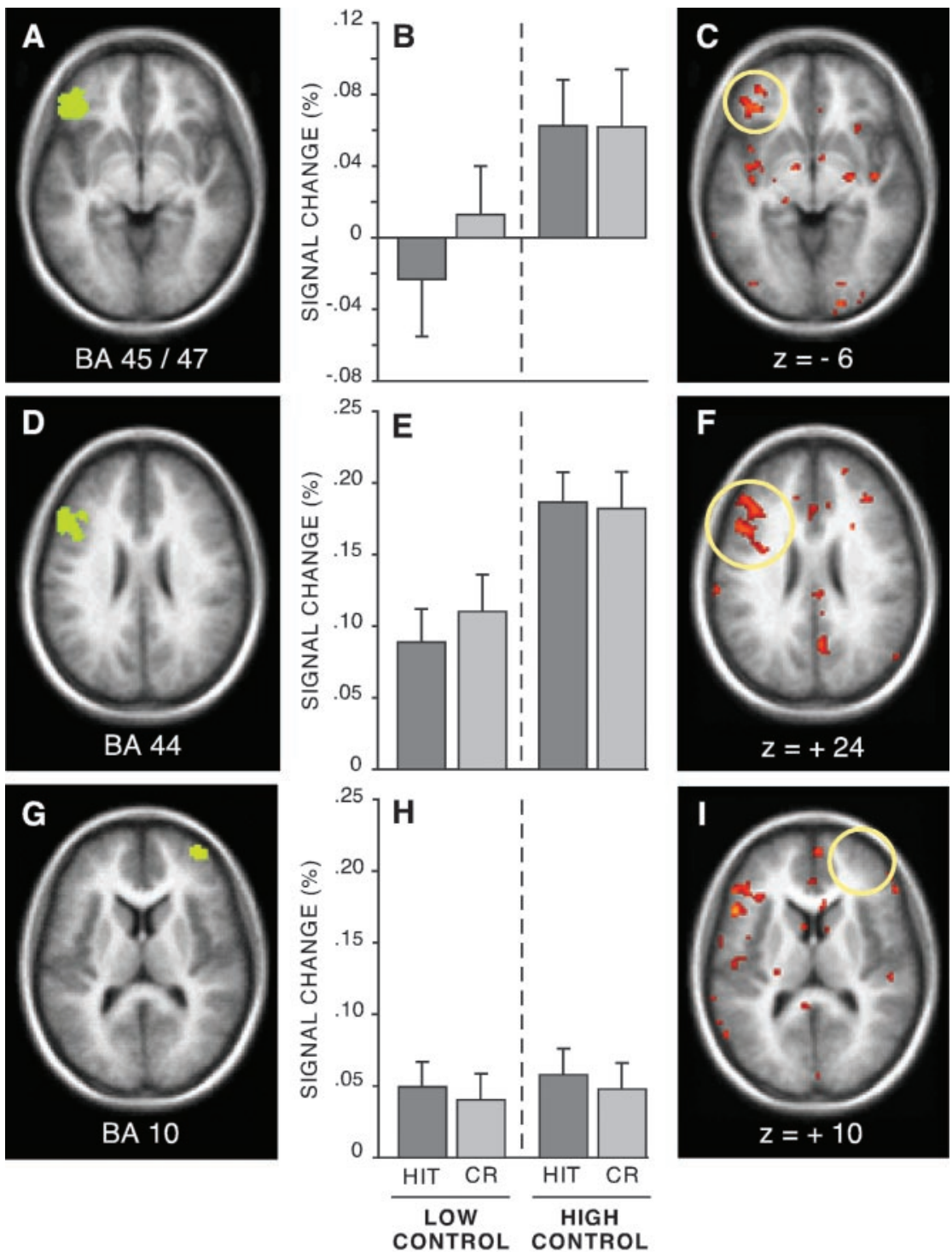

CONTROL CONTROL

Figure 4. $\quad \operatorname{aLIPC}(A-C)$ and $\mathrm{pLIPC}(D-F)$ increased activity in the high versus low control condition. No trial-related modulation by level of control or response was observed in right frontal-polar cortex $(G-l)$. The panel layout parallels that of Figure 3. For sections showing statistical activation in the high control condition relative to the low control condition, thresholds are set at $z=$ 2.58, $p=0.01$, two-tailed.

heterogeneous and can show dissociable patterns of activation consistent with the proposed dissociation of these regions. Replicating this dissociation, in the present study, a region at or near BA 6 showed no significant modulation of BOLD response by control condition $\left(F_{(1,28)}=0.65 ; p>0.43\right)$ or response $\left(F_{(1,28)}=\right.$ $2 ; p>0.17)$. Rather, all trial types showed an equivalent level of BOLD signal change. No significant modulation of signal magnitude by response or control condition was observed, but a significant main effect of time was obtained when time courses were considered $\left(F_{(6,168)}=36.76 ; p<0.001\right)$.

Finally, we examined transient activation changes in a rightlateralized region of frontal-polar cortex at or near BA 10 (McDermott et al., 1999) (Fig. 4G). Similar regions at or near BA 10 have been shown to be active across various episodic retrieval tasks (Table 1) (for review, see Buckner, 1996; Nyberg et al., 1996). Relative to more posterior regions of frontal cortex, frontal-polar cortex, particularly on the right, is more selectively involved in tasks that require retrieval of episodic information (whether verbal or nonverbal) but is not always active during other controlled verbal or nonverbal processing tasks [but see MacLeod et al. (1998) and Koechlin et al. (1999)]. Furthermore, transient effects in right frontal-polar cortex sometimes show atypically delayed and prolonged responses in event-related fMRI studies (Schacter et al., 1997; Buckner et al., 1998b; Henson et al., 2000). Moreover, several authors have suggested that right frontal-polar cortex functions to provide ongoing monitoring during retrieval, leading to the possibility that activity in this region reflects sustained as opposed to transient processing components.

Consistent with this possibility, no significant transient changes in the BOLD response were observed in right frontalpolar cortex. As depicted in Figure $4 \mathrm{H}$, right BA 10 showed no significant modulation of BOLD response by control condition $\left(F_{(1,28)}=0.27 ; p>0.5\right)$ or response $\left(F_{(1,28)}=1.61 ; p>0.2\right)$. Rather, across conditions, the magnitude of the BOLD response did not differ. In light of previous findings showing delayed responses in right frontal-polar cortex, the magnitude of responses in this region was also estimated after delays of 4, 6, and $8 \mathrm{sec}$ (in addition to our assumed delay of $2 \mathrm{sec}$ ). In no case was the transient BOLD response found to differ significantly from baseline. These results converge with findings reported recently by Wheeler and Buckner (2003). By contrast, right BA 10 did show significant sustained signal changes, as discussed in the next section.

\section{Sustained effect}

Magnitudes of sustained effects were estimated for each of the six regions of interest (Table 1). Three regions, a region in pLIPC near BA 6, left lateral parietal cortex near BA 40/39, and perhaps most notably, right frontal-polar cortex near BA 10 showed sustained effects that diverged significantly from baseline. First, BA 6 showed sustained modulations that reflected significantly decreased activity in the low control condition relative to baseline $\left(t_{(28)}=-3.26 ; p<0.01\right.$; two-tailed, as elsewhere), but sustained activity in the high control condition did not differ $\left(t_{(28)}=\right.$ $-0.72 ; p>0.4$ ). In both left lateral parietal cortex (near BA 40/39) and right BA 10, sustained BOLD responses were significantly increased in the high control condition relative to baseline $t_{(28)}=4.20, p<0.001$ for BA $40 / 39 ; t_{(28)}=3.38, p<0.01$ for BA $10)$ but did not differ for the low control condition $\left(t_{(28)}=0.31\right.$, $p>0.7$ for BA $40 / 39 ; t_{(28)}=0.86, p>0.39$ for BA 10). Sustained activity in the high control condition was compared directly with that in the low control condition for each of these three regions. The high control condition showed significantly greater sustained activity than the low control condition in BA 6 and BA $40 / 39\left(t_{(28)}=2.16, p<0.05\right.$ for BA $6 ; t_{(28)}=3.33, p<.005$ for BA $40 / 39)$, but although there was a qualitative difference, this com- 

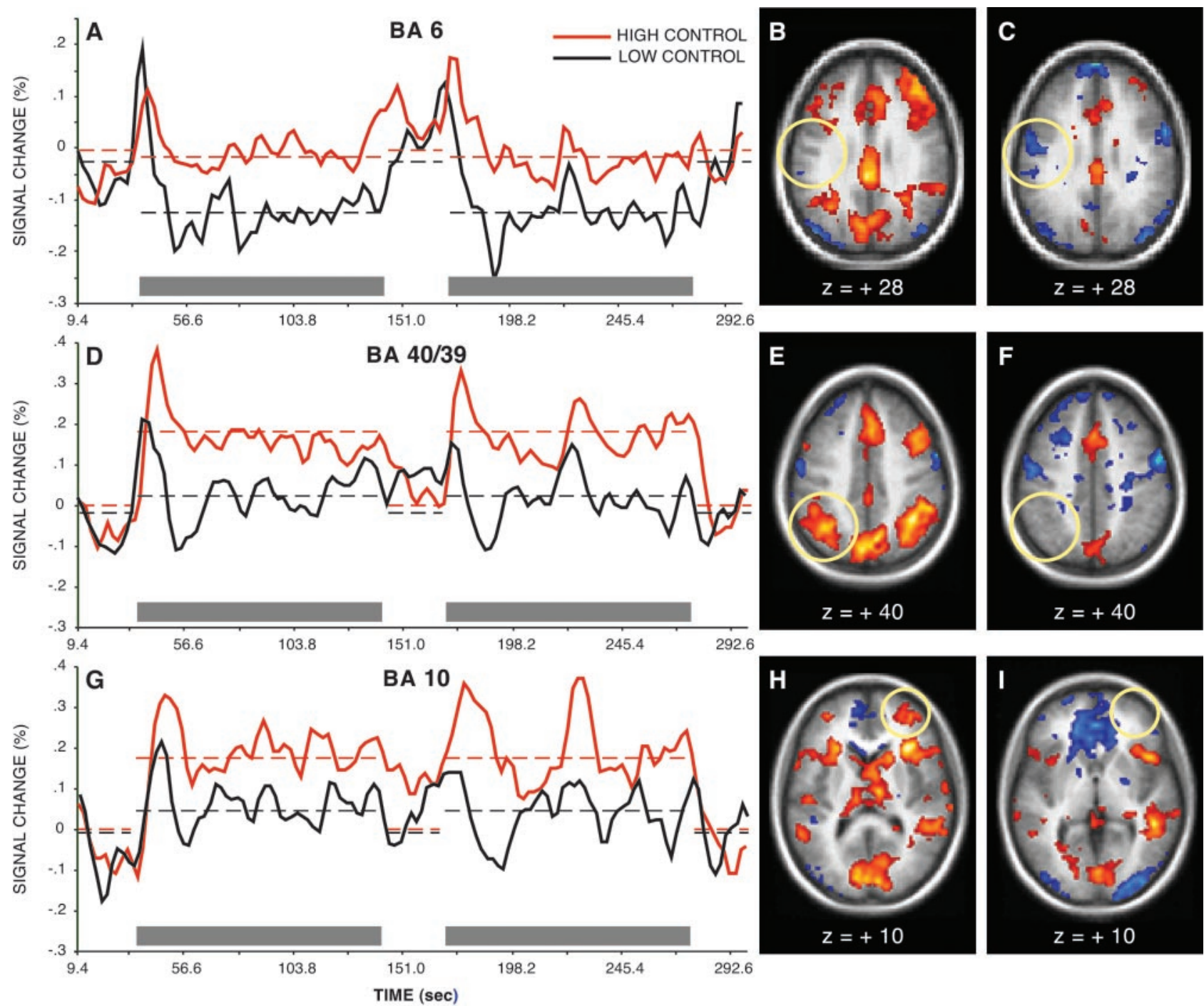

Figure 5. pLIPC (near BA6), left lateral parietal cortex, and right frontal-polar cortex showed significant changes in sustained activity across task blocks. Time courses for these effects are depicted. pLIPC (near BA 6) showed significantly decreased sustained activity in the low control condition relative to baseline and relative to the high control condition $(A)$. Left lateral parietal cortex ( $D$ ) and right frontal-polar cortex $(G)$ showed significantly increased sustained activity in the high control condition relative to baseline, and also for left lateral parietal cortex, relative to the low control condition. In $A, D$, and $G$, gray bars represent task periods. Broken lines represent mean sustained activity during task periods and during periods of fixation. Regions showing significant sustained activity in the high control condition are depicted in $B, E$, and $H$. Regions showing significant sustained activity in the low control condition are depicted in $C, F$, and $I$. Thresholds are set at $z= \pm 1.96$; $p=0.05$, two-tailed. Approximate locations of regions explored in hypothesis-directed analyses, for which sustained time courses are depicted, are circled.

parison failed to reach significance in right BA $10\left(t_{(28)}=1.52\right.$; $p=0.14)$. Time courses for these effects are depicted in Figure 5.

\section{Exploratory analyses}

Whole-brain exploratory analyses revealed several regions showing transient modulations in the BOLD response on the basis of retrieval success, including regions investigated in hypothesisdriven analyses (Fig. 6A). Hits led to increased activity in left anterior frontal cortex at or near BA 10/46, bilateral parietal cortex overlapping BA 40/39, medial parietal cortex, posterior cingulate/precuneus, and bilateral parahippocampal gyrus (extending into or near hippocampus proper) relative to correct rejections.

The differing levels of controlled processing produced changes in transient activity in various brain regions, again including regions investigated in hypothesis-directed analyses (Fig. $6 B)$. Increased BOLD responses were observed for the high control relative to the low control condition in left dorsal and inferior frontal cortex, bilateral inferior temporal cortex, lateral and me- dial parietal cortex, and medial frontal cortex. For all exploratory analyses involving transient effects, thresholds were set at $z=$ 2.58, $p=0.01$, two-tailed.

In common with previous studies using mixed blocked eventrelated designs (Donaldson et al., 2001; Burgund et al., 2003), an extensive network of regions showed sustained activity (Fig. $6 C, D)$. Positive activity in both the high and low control conditions was evident in medial frontal cortex, medial occipital cortex, bilateral frontal opercular/insular cortex, bilateral middle temporal gyrus, cingulate gyrus, and bilateral cerebellum. In both conditions, negative activity was observed in medial frontal cortex (ventral to the positive activations) and bilateral occipitalparietal cortex. Additionally, several regions showed increased sustained activity only in the high control condition. These regions included right dorsal frontal cortex, bilateral lateral parietal cortex, and right frontal-polar cortex. Here, thresholds were set at $z= \pm 2.58, p=0.01$, two-tailed. A direct comparison of sustained activity in the high and low control conditions revealed increased sustained activity in the high control relative to the low control 
A

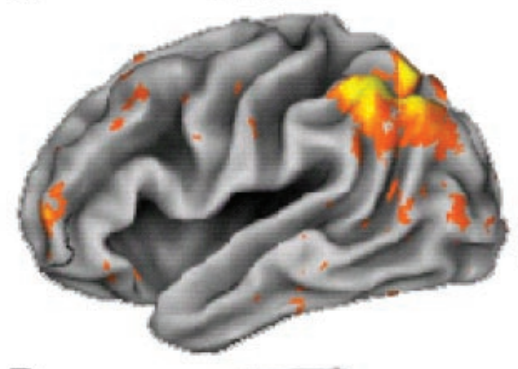

B

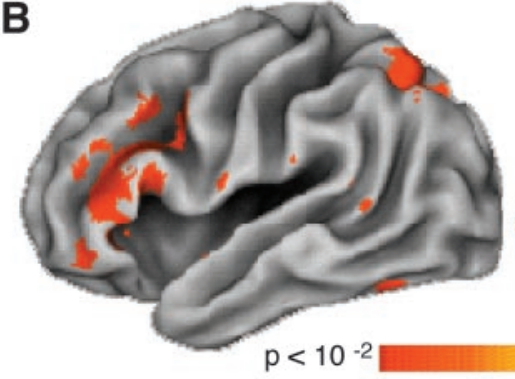

C

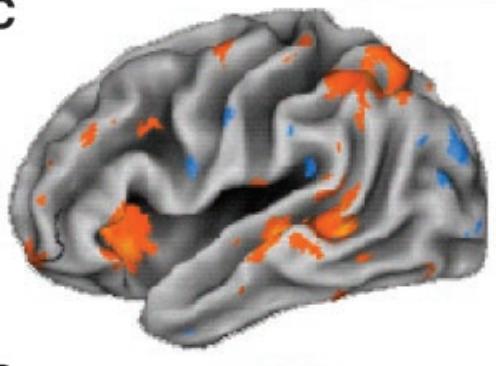

D

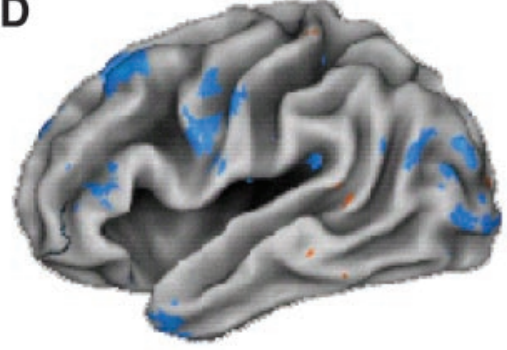

$\mathrm{p}<10^{-10}$
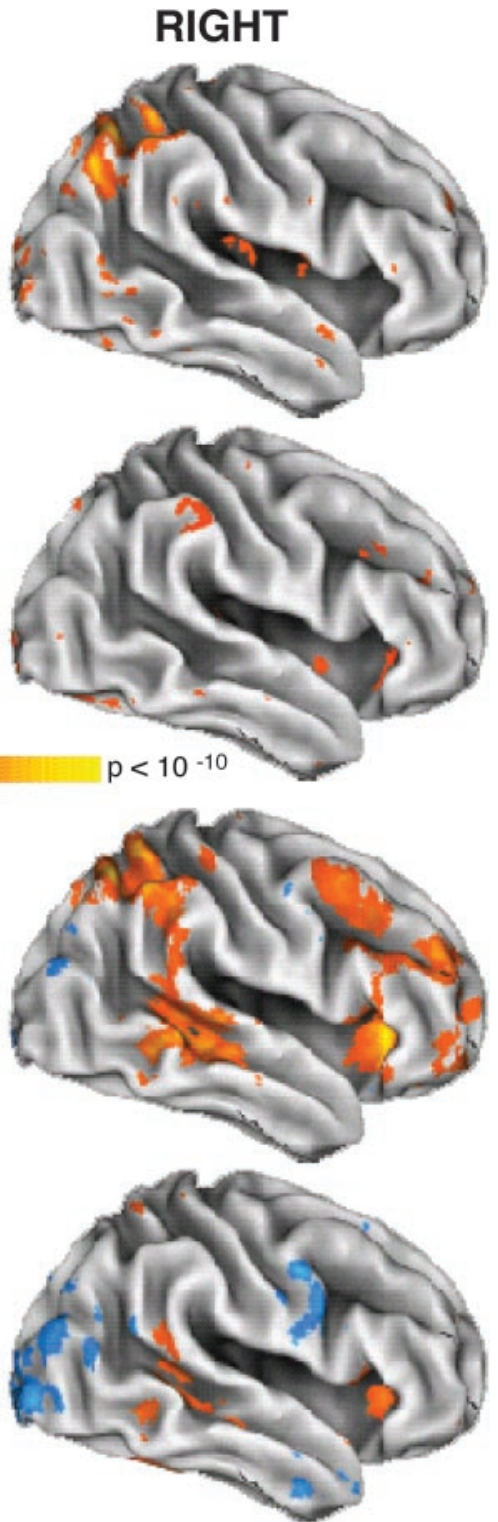

$\mathrm{p}<10^{-2}$

$\mathrm{p}<10-10$
Figure 6. $A, B$, Exploratory statistical activation maps based on ANOVA from item contrasts show regions that were transiently modulated. A, Activation maps show regions that modulated differentially for HIT relative to CR trials. B, Activation maps show regions that modulated differentially for high relative to low control trials. Level of significance scale is shown in the color scale bar below $B$. Note that because these maps derive from ANOVA interaction terms, direction of effects is not represented. $C, D$, Exploratory voxel-based statistical activation maps on the basis of $t$ statistics show regions that modulated in a sustained manner. C, Activation maps show significant modulation for the high control condition. D, Activation maps show significant modulation for the low control condition. Level of significance is shown in the color scale bar below $D$. All activation maps are shown projected onto representative inflated cortical surfaces.

condition in bilateral dorsal frontal cortex, inferior frontal cortex, lateral parietal cortex, opercular-insular cortex, left middle temporal gyrus, and a region in right frontal-polar cortex, partially overlapping with, but not identical to, the region explored in hypothesis-directed analyses. For this comparison, thresholds were set at $z= \pm 1.96, p=0.05$, two-tailed. Because of this liberal criterion, these exploratory activations are presented as tentative candidates for future investigation. All data interpreted in the present paper derive from analyses of activity in a priori-defined regions meeting strict statistical criteria in hypothesis-directed analyses. (Complete coordinate lists for all exploratory effects can be obtained from the authors on request.)

\section{Discussion}

The present study investigated neural correlates of controlled processing components engaged during episodic retrieval using a mixed blocked event-related design (Donaldson and Buckner, 2001; Donaldson et al., 2001; Otten et al., 2002; Visscher et al., 2003a). Functional dissociation across regions subserving sustained and transient processes was noted within frontal cortex. Of particular interest, right frontal-polar cortex (at or near BA 10) contributed to sustained control processes in the absence of trial-related effects, providing direct evidence of a role for right frontal-polar cortex in retrieval mode (Tulving, 1983). Taken in the context of trial-associated activity in more posterior frontal regions, this result provides support for a hierarchy of controlled processing resources in frontal cortex, with frontal-polar regions contributing to a set, or mode, that interacts with more posterior frontal regions that guide retrieval on a trial-by-trial basis [see also Sakai et al. (2002)]. Intentional uses of memory, such as recollection (Mandler, 1980; Jacoby, 1991), may depend on this hierarchy of processing resources. The finding that right frontal-polar contributions to retrieval include a sustained component also reconciles a number of discrepant findings that have arisen when contrasting blocked-trial paradigms with event-related paradigms.

\section{Right frontal-polar cortex participates in sustained control processes}

Consistent with previous neuropsychological explorations (for review, see Schacter, 1987; Shimamura et al., 1991; Wheeler et al., 1995), a large number of human imaging studies have noted frontal contributions to episodic memory retrieval (for review, see Fletcher et al., 1998; Cabeza and Nyberg, 2000; Buckner, 2003). Because of methodological limitations, early blocked paradigms averaged activity over extended epochs during which many retrieval attempts were performed in rapid succession (Squire et al., 1992). Right frontal activity, particularly within frontal-polar cortex near BA 10, was almost always observed during these studies (for review, see Buckner, 1996; Nyberg et al.,1996). By contrast, more recent event-related paradigms that explore activity time-locked to individual trials note right frontal-polar activity less often or report activity that is atypically prolonged in time (Schacter et al., 1997) [see also Rugg and Henson (2002) for a recent review of event-related findings].

One possible factor contributing to these complicated findings is that right frontal-polar cortex (near BA 10) plays a role in forming and maintaining an attentional set, or task mode, that extends over multiple individual retrieval attempts (Nyberg et al., 
1995; Düzel et al., 1999). Many kinds of systems require statedependent gating such that information is handled differently depending on the operational task at hand (Buckner, 2003). Right frontal-polar cortex may contribute to gating processes in the cognitive domain, helping to maintain cognitive set during retrieval, particularly when a retrieval task requires that one constrain retrieval to a specific past context. Düzel and colleagues (1999) provided initial evidence that frontal-polar contributions to retrieval may be sustained by combining data from DCrecorded event-related potentials and positron emission tomography (PET). Participants were presented with sets of four-item test lists and were cued to make either semantic (animacy) or recognition judgments. Cues signaling the recognition task elicited a sustained positive shift over right frontal scalp electrodes, consistent with findings from an analogous PET study, which revealed activation in right frontal-polar cortex. In accord with the results presented here, Düzel et al. (1999) interpreted their findings as providing evidence for the role of right frontal-polar cortex in forming and maintaining a sustained task mode specific to episodic retrieval.

In the present study, direct dissociation of sustained and transient contributions to controlled processing showed that right frontal-polar cortex activity can be sustained during episodic memory retrieval. The absence of such an effect during the low control condition tentatively suggests that frontal-polar contributions are modulated by the level of control required; however, further studies that have more power for direct contrasts among retrieval conditions will be required to support this possibility more strongly. In addition, further investigations are warranted to explore sustained and transient responses in paradigms that have suggested some level of transient modulation in right BA10 (McDermott et al., 2000; Rugg et al., 2003).

\section{Efficacy of the mixed blocked event-related design}

The sustained activity in right frontal-polar cortex observed in our high control condition occurred in the absence of significant trial-related effects. This result goes some way toward addressing concerns that sustained activity might reflect "spillover" from transient responses (Visscher et al., 2003a). The present findings reveal that some regions exhibit predominantly sustained activity, whereas others exhibit predominantly transient changes (e.g., aLIPC, near BA 45/47). Still other regions showed concurrent sustained and transient responses.

Notably, left lateral parietal cortex showed transient effects that modulated predominantly on the basis of the mnemonic status of an item, with hits producing greater signal change than correct rejections. This transient activity was set against a background of sustained activity that modulated with level of control. Left dorsal frontal cortex near BA 6 also showed significant transient modulations relative to baseline across all trial conditions, but sustained activity was evident only in the low control condition, and this activity presented as significant negative change.

Although only limited mixed blocked event-related designs (or variants thereof) have been reported (Donaldson et al., 2001; Otten et al., 2002; Burgund et al., 2003; Visscher et al., 2003b), consistencies across studies are beginning to emerge. Several regions (e.g., bilateral frontal operculum/insular cortex and medial frontal cortex) show sustained activity across experiments. These regions represent good candidates for supporting task-general control signals, at least in the lexical domain, because all experiments reported thus far have used verbal materials. In contrast, sustained activity in right frontal-polar cortex, as observed in the present study, seems to modulate in a task-specific manner, with data from blocked designs implying that this region might show similar activation across changes in stimulus modality and retrieval task. We do not anticipate that frontal-polar contributions will be specific to episodic retrieval (Buckner, 2003) but rather will be required during subsets of tasks that demand certain kinds of task control, such as controlled recognition, and also during some working memory and decision tasks (Koechlin et al., 1999; Braver and Bongiolatti, 2002).

\section{Regions within frontal cortex dissociate on the basis of their temporal profiles}

The present findings demonstrate functional dissociations among regions within frontal cortex. Right frontal-polar cortex showed sustained modulation in the high control condition, in direct contrast to aLIPC and the anterior portion of pLIPC (near BA 45/47 and BA 44, respectively), which showed transient modulation. Both aLIPC and pLIPC were strongly activated in the high control condition relative to the low control condition (Fig. 4) and similarly so for hits and correct rejections.

Within frontal cortex, aLIPC (near BA 45/47) and pLIPC (near BA44) are frequently reported to be active during tasks that require controlled retrieval of information, particularly (but not exclusively) within the semantic domain (Petersen et al., 1989; Raichle et al., 1994; Demb et al., 1995; Roskies et al., 2001; Wagner et al., 2001b; Gold and Buckner, 2002; Nyberg et al., 2003). Related modulations have been observed directly in episodic memory retrieval tasks (Nolde et al., 1998a; Rugg et al., 1999; Ranganath et al., 2000; Wagner et al., 2001a; Dobbins et al., 2002; Konishi et al., 2002; Cabeza et al., 2003; Nyberg et al., 2003; Wheeler and Buckner, 2003). On the basis of these findings, it has been suggested that these prefrontal regions are important in controlled retrieval or selection from among competing representations during many forms of retrieval, including semantic elaboration (Thompson-Schill et al., 1997). Consistent with these characterizations, in the present study, aLIPC and pLIPC showed significantly greater activation in the high control relative to the low control condition regardless of whether participants were responding to studied targets or new lures (i.e., with hits or correct rejections) [see also Dobbins et al. (2002); Cabeza et al. (2003); Wheeler et al. (2003)].

One speculative possibility is that aLIPC and the anterior portion of pLIPC near BA 44 that modulate on a trial-by-trial basis during retrieval form a hierarchy of processing resources with frontal-polar cortex (near BA10). Frontal-polar cortex may contribute to establishing an attentional set, or retrieval mode, that interacts with more posterior frontal regions that enable search and evaluation processes deployed on the basis of momentary processing demands.

A further dissociation was noted in that left anterior frontal cortex near BA 10/46 (and left lateral parietal cortex near BA 40/39) increased activity during retrieval of studied items (i.e., for hits) relative to the identification of new items (i.e., for correct rejections), independent of level of control. This result is in accord with previous studies comparing hits with correct rejections (Habib and Lepage, 1999; Konishi et al., 2000). We interpret this finding as demonstrating that left anterior frontal cortex modulates on the basis of the perception of oldness rather than on retrieval success, as such modulation is sometimes described. This interpretation is on the basis of related studies (Wheeler and Buckner, 2003) showing that left anterior frontal cortex and left lateral parietal cortex increase activity when participants decide that items are old, regardless of whether items are actually old or new. 


\section{Conclusions}

Using mixed blocked event-related fMRI, the present study demonstrates that regions subserving sustained and transient processes involved in retrieval can be functionally dissociated. Most notably, a region in right frontal-polar cortex near BA 10 exhibited prominent sustained signal changes. aLIPC (near BA 45/47) and anterior pLIPC (near BA 44) modulated with level of control but did so on a transient trial-by-trial basis. These multiple frontal regions may provide dissociable processing resources to retrieval tasks and other forms of task outside the domain of memory retrieval that require high levels of controlled processing.

\section{References}

Boynton GM, Engel SA, Glover GH, Heeger DJ (1996) Linear systems analysis of functional magnetic resonance imaging in human V1. J Neurosci 16:4207-4221.

Braver TS, Bongiolatti SR (2002) The role of frontopolar cortex in subgoal processing during working memory. NeuroImage 15:523-536.

Buckner RL (1996) Beyond HERA: contributions of specific prefrontal brain areas to long-term memory retrieval. Psychon Bull Rev 3:149-158.

Buckner RL (2003) Functional-anatomic correlates of control processes in memory. J Neurosci 23:3999-4004.

Buckner RL, Raichle ME, Petersen SE (1995a) Dissociation of human prefrontal cortical areas across different speech production tasks and gender groups. J Neurophysiol 74:2163-2173.

Buckner RL, Petersen SE, Ojemann JG, Miezin FM, Squire LR, Raichle ME (1995b) Functional anatomical studies of explicit and implicit memory retrieval tasks. J Neurosci 15:12-29.

Buckner RL, Raichle ME, Miezin FM, Petersen SE (1996) Functional anatomic studies of memory retrieval for auditory words and visual pictures. J Neurosci 16:6219-6235.

Buckner RL, Koutstaal W, Schacter DL, Wagner AD, Rosen BR (1998a) Functional-anatomic study of episodic retrieval using fMRI. I. Retrieval effort versus retrieval success. NeuroImage 7:151-162.

Buckner RL, Koutstaal W, Schacter DL, Dale AM, Rotte MR, Rosen BR (1998b) Functional-anatomic study of episodic retrieval. II. Selective averaging of event-related fMRI trials to test the retrieval success hypothesis. NeuroImage 7:163-175.

Buckner RL, Wheeler ME, Sheridan MA (2001) Encoding processes during retrieval tasks. J Cognit Neurosci 13:406-415.

Bundeson C (1999) A computational theory of visual attention. In: Attention, space and action: studies in cognitive neuroscience (Humphreys GW, Duncan J, Treisman A, eds), pp 54-71. London: Oxford UP.

Burgund ED, Lugar HM, Miezin FM, Petersen SE (2003) Sustained and transient activity during an object-naming task: a mixed blocked and event-related fMRI study. NeuroImage 19:29-41.

Cabeza R, Nyberg L (2000) Imaging cognition II: An empirical review of 275 PET and fMRI studies. J Cognit Neurosci 12:1-47.

Cabeza R, Locantore JK, Anderson ND (2003) Lateralization of prefrontal activity during episodic memory retrieval: evidence for the productionmonitoring hypothesis. J Cognit Neurosci 15:249-259.

Chawla D, Rees G, Friston KJ (1999) The physiological basis of attentional modulation in extrastriate visual areas. Nat Neurosci 2:671-676.

Cohen JD, MacWhinney B, Flatt M, Provost J (1993) PsyScope: a new graphic interactive environment for designing psychology experiments. Behav Res Methods Instrum Comput 25:257-271.

Conturo TE, McKinstry RC, Akbudak E, Snyder AZ, Yang TZ, Raichle ME (1996) Sensitivity optimization and experimental design in functional magnetic resonance imaging. Soc Neurosci Abstr 22:7.

Demb JB, Desmond JE, Wagner AD, Vaidya CJ, Glover GH, Gabrieli JDE (1995) Semantic encoding and retrieval in the left inferior prefrontal cortex: a functional MRI study of task difficulty and process specificity. J Neurosci 15:5870-5878.

Desimone R, Duncan J (1995) Neural mechanisms of selective visual attention. Annu Rev Neurosci 18:193-222.

Dobbins IG, Foley H, Schacter DL, Wagner AD (2002) Executive control during episodic retrieval: multiple prefrontal processes subserve source memory. Neuron 35:989-996.

Donaldson DI, Buckner RL (2001) Effective paradigm design. In: Functional MRI: an introduction to methods (Jezzard P, Matthews PM, Smith SM, eds), pp 177-195. London: Oxford UP.
Donaldson DI, Petersen SE, Ollinger JM, Buckner RL (2001) Dissociating state and item components of recognition memory using fMRI. NeuroImage 13:129-142.

Düzel E, Cabeza R, Picton TW, Yonelinas AP, Scheich H, Heinze HJ, Tulving E (1999) Task-related and item-related brain processes of memory retrieval. Proc Natl Acad Sci USA 96:1794-1799.

Düzel E, Picton TW, Cabeza R, Yonelinas AP, Scheich H, Heinze HJ, Tulving E (2001) Comparative electrophysiological and hemodynamic measures of neural activation during memory-retrieval. Hum Brain Mapp 13:104-123.

Fletcher PC, Shallice T, Frith CD, Frackowiak RS, Dolan RJ (1998) The functional roles of prefrontal cortex in episodic memory. II. Retrieval. Brain 121:1249-1256.

Friston KJ, Holmes AP, Poline JB, Grasby PJ, Williams SC, Frackowiak RS, Turner R (1995) Analysis of fMRI time-series revisited. NeuroImage 2:45-53.

Friston KJ, Williams S, Howard R, Frackowiak RS, Turner R (1996) Movement-related effects in fMRI time-series. Magn Reson Med 35:346-355.

Gabrieli JDE, Poldrack RA, Desmond DE (1998) The role of left prefrontal cortex in language and memory. Proc Natl Acad Sci USA 95:906-913.

Gold BT, Buckner RL (2002) Common prefrontal regions coactivate with dissociable posterior regions during controlled semantic and phonological tasks. Neuron 35:803-812.

Habib R, Lepage M (1999) Novelty assessment in the brain. In: Memory, consciousness, and the brain (Tulving E, ed), pp 265-277. Philadelphia: Psychology Press.

Henson RN, Shallice T, Dolan RJ (1999a) Right prefrontal cortex and episodic memory retrieval: a functional MRI test of the monitoring hypothesis. Brain 122:1367-1381.

Henson RN, Rugg MD, Shallice T, Josephs O, Dolan RJ (1999b) Recollection and familiarity in recognition memory: an event-related functional magnetic resonance imaging study. J Neurosci 19:3962-3972.

Henson RN, Rugg MD, Shallice T, Dolan RJ (2000) Confidence in recognition memory for words: dissociating right prefrontal roles in episodic retrieval. J Cognit Neurosci 12:913-923.

Jacoby LL (1991) A process dissociation framework: separating automatic from intentional uses of memory. J Memory Language 30:513-541.

Jacoby LL, Dallas M (1981) On the relationship between autobiographical memory and perceptual learning. J Exp Psychol Gen 110:306-340.

Jonides J, Schumacher EH, Smith EE, Koeppe RA, Awh E, Reuter-Lorenz PA, Marshuetz C, Willis CR (1998) The role of parietal cortex in verbal working memory. J Neurosci 18:5026-5034.

Koechlin E, Basso G, Pietrini P, Panzer S, Grafman J (1999) The role of the anterior prefrontal cortex in human cognition. Nature 399:148-151.

Konishi S, Wheeler ME, Donaldson DI, Buckner RL (2000) Neural correlates of episodic retrieval success. NeuroImage 12:276-286.

Konishi S, Uchida I, Okuaki T, Machida T, Shirouzu I, Miyashita Y (2002) Neural correlates of recency judgment. J Neurosci 22:9549-9555.

Koriat A (2000) Control processes in remembering. In: The Oxford handbook of memory (Tulving E, Craik FIM, eds), pp 333-346. New York: Oxford UP.

Kucera H, Francis WN (1967) Computational analysis of present-day American English. Providence, RI: Brown UP.

Lepage M, Ghaffar O, Nyberg L, Tulving E (2000) Prefrontal cortex and episodic memory retrieval mode. Proc Natl Acad Sci USA 97:506-511.

Logan JM, Sanders AL, Snyder AZ, Morris JC, Buckner RL (2002) Underrecruitment and nonselective recruitment: dissociable neural mechanisms associated with aging. Neuron 33:827-840.

Maccotta L, Zacks JM, Buckner RL (2001) Rapid self-paced event-related functional MRI: feasibility and implications of stimulus-versus responselocked timing. NeuroImage 14:1105-1121.

MacLeod AK, Buckner RL, Miezin FM, Petersen SE, Raichle ME (1998) Right anterior prefrontal cortex activation during semantic monitoring and working memory. NeuroImage 7:41-48.

Mandler G (1980) Recognizing: the judgment of previous occurrence. Psychol Rev 87:252-271.

McDermott KB, Buckner RL, Petersen SE, Kelley WM, Sanders AL (1999) Set- and code-specific activation in the frontal cortex: an fMRI study of encoding and retrieval of faces and words. J Cognit Neurosci 11:631-640.

McDermott KB, Jones TC, Petersen SE, Lageman SK, Roediger III HL (2000) Retrieval success is accompanied by enhanced activation in anterior pre- 
frontal cortex during recognition memory: an event-related fMRI study. J Cognit Neurosci 12:965-976.

McDermott KB, Petersen SE, Watson J, Ojemann JG (2003) A procedure for identifying regions preferentially activated by attention to semantic and phonological relations using functional magnetic resonance imaging. Neuropsychologia 41:293-303.

Miezin FM, Maccotta L, Ollinger J, Petersen SE, Buckner RL (2000) Characterizing the hemodynamic response: effects of presentation rate, sampling procedure, and the possibility of ordering brain activity based on relative timing. NeuroImage 11:735-759.

Nolde SF, Johnson MK, Raye CL (1998a) The role of prefrontal cortex during tests of episodic memory. Trends Cogn Sci 2:399-406.

Nolde SF, Johnson MK, D’Esposito M (1998b) Left prefrontal activation during episodic remembering: an event-related fMRI study. NeuroReport 9:3509-3514

Nyberg L, Tulving E, Habib R, Nilsson L-G, Kapur S, Houle S, Cabeza R, McIntosh AR (1995) Functional brain maps of retrieval mode and recovery of episodic information. NeuroReport 7:249-252.

Nyberg L, Cabeza R, Tulving E (1996) PET studies of encoding and retrieval: the HERA model. Psychon Bull Rev 3:135-148.

Nyberg L, Marklund P, Persson J, Cabeza R, Forkstam C, Magnus-Petersson K, Ingvar M (2003) Common prefrontal activation during working memory, episodic memory, and semantic memory. Neuropsychologia 41:371-377.

Otten LJ, Henson RN, Rugg MD (2002) State-related and item-related neural correlates of successful memory encoding. Nat Neurosci 5:1339-1344.

Petersen SE, Fox PT, Posner MI, Mintun M, Raichle ME (1989) Positron emission tomographic studies of the processing of single words. J Cognit Neurosci 1:153-170.

Poldrack RA, Wagner AD, Prull MW, Desmond JE, Glover GH, Gabrieli JDE (1999) Functional specialization for semantic and phonological processing in the left inferior prefrontal cortex. NeuroImage 10:15-35.

Raichle ME, Fiez JA, Videen TO, MacLeod A-MK, Pardo JV, Fox PT, Petersen SE (1994) Practice-related changes in human brain functional anatomy during nonmotor learning. Cereb Cortex 4:8-26.

Ranganath C, Johnson MK, D'Esposito M (2000) Left anterior prefrontal activation increases with demands to recall specific perceptual information. J Neurosci 20:RC108(1-5).

Roskies AL, Fiez JA, Balota DA, Raichle ME, Petersen SE (2001) Taskdependent modulation of regions in the left inferior frontal cortex during semantic processing. J Cognit Neurosci 13:829-843.

Rugg MD, Henson RN (2002) Episodic retrieval: an (event-related) functional neuroimaging perspective. In: The cognitive neuroscience of memory: encoding and retrieval (Parker A, Wilding E, Bussey T, eds), pp 3-37. Hove, New York: Psychology Press.

Rugg MD, Wilding EL (2000) Retrieval processing and episodic memory. Trends Cogn Sci 4:108-115.

Rugg MD, Fletcher PC, Frith CD, Frackowiak RSJ, Dolan RJ (1996) Differential response of the prefrontal cortex in successful and unsuccessful memory retrieval. Brain 119:2073-2083.

Rugg MD, Fletcher PC, Allan K, Frith CD, Frackowiak RS, Dolan RJ (1998) Neural correlates of memory retrieval during recognition memory and cued recall. NeuroImage 8:262-273.

Rugg MD, Fletcher PC, Chua PM, Dolan RJ (1999) The role of the prefrontal cortex in recognition memory and memory for source: an fMRI study. NeuroImage 10:520-529.

Rugg MD, Henson RNA, Robb WGK (2003) Neural correlates of retrieval processing in prefrontal cortex during recognition and exclusion tasks. Neuropsychologia 41:40-52.

Sakai K, Rowe JB, Passingham RE (2002) Active maintenance in prefrontal area 46 creates distractor-resistant memory. Nat Neurosci 5:479-484.

Schacter DL (1987) Memory, amnesia, and frontal lobe dysfunction. Psychobiology 15:21-36.
Schacter DL, Buckner RL, Koutstaal W, Dale AM, Rosen BR (1997) Late onset of anterior prefrontal activity during true and false recognition: an event-related fMRI study. NeuroImage 6:259-269.

Schneider W, Shiffrin RM (1977) Controlled and automatic human information processing: I. Detection, search, and attention. Psychol Rev 84:1-66.

Shiffrin RM, Schneider W (1977) Controlled and automatic human information processing: II. Perceptual learning, automatic attending and a general theory. Psychol Rev 84:127-190.

Shimamura AP, Janowsky JS, Squire LR (1991) What is the role of frontal lobe damage in memory disorders? In: Frontal lobe function and dysfunction (Levin H, Eisenberg HM, Benton AL, eds), pp 173-195. New York: Oxford UP.

Snyder AZ (1996) Difference image versus ratio image error function forms in PET-PET realignment. In: Quantification of brain function using PET (Bayley D, Jones T, eds), pp 131-137. San Diego: Academic.

Squire LR, Ojemann JG, Miezin FM, Petersen SE, Videen TO, Raichle ME (1992) Activation of the hippocampus in normal humans: a functional anatomical study of memory. Proc Natl Acad Sci USA 89:1837-1841.

Talairach J, Tournoux P (1988) Co-planar stereotaxic atlas of the human brain. New York: Thieme.

Thompson-Schill SL, D’Esposito M, Aquirre GK, Farah MJ (1997) Role of left inferior prefrontal cortex in retrieval of semantic knowledge: a reevaluation. Proc Natl Acad Sci USA 94:14792-14797.

Tulving E (1983) Elements of episodic memory. New York: Oxford UP.

Tulving E, Pearlstone Z (1966) Availability versus accessibility of information in memory for words. J Verbal Learn Verbal Behav 5:381-391.

Tulving E, Kapur S, Craik FIM, Moscovitch M, Houle S (1994) Hemispheric encoding/retrieval asymmetry in episodic memory: positron emission tomography findings. Proc Natl Acad Sci USA 91:2016-2020.

Van Essen DC, Drury HA, Dickson J, Harwell J, Hanlon D, Anderson CH (2001) An integrated software suite for surface-based analyses of cerebral cortex. J Am Med Inform Assoc 8:443-459.

Visscher KM, Miezin FM, Kelly JE, Buckner RL, Donaldson DI, McAvoy MP, Bhalodia VM, Petersen SE (2003a) Mixed blocked/event-related designs separate transient and sustained activity in fMRI. NeuroImage, in press.

Visscher KM, Palmer ED, Burgund ED, Kang HC, Miezin FM, Lyon JK, Buckner RL, Petersen SE (2003b) Sustained, block-related activity compared across four tasks shows both common and task modulated responses. Cognit Neurosci Soc Abstr 10:97.

Wagner AD, Desmond JE, Glover GH, Gabrieli JDE (1998) Prefrontal cortex and recognition memory: functional-MRI evidence for contextdependent retrieval processes. Brain 121:1985-2002.

Wagner AD, Koutstaal W, Maril A, Schacter DL, Buckner RL (2000) Taskspecific repetition priming in left inferior prefrontal cortex. Cereb Cortex 10:1176-1184.

Wagner AD, Maril A, Bjork RA, Schacter DL (2001a) Prefrontal contributions to executive control: fMRI evidence for functional distinctions within lateral prefrontal cortex. NeuroImage 14:1337-1347.

Wagner AD, Pare-Blagoev EJ, Clark J, Poldrack RA (2001b) Recovering meaning: left prefrontal cortex guides controlled semantic retrieval. Neuron 31:329-338.

Wheeler MA, Stuss DT, Tulving E (1995) Frontal lobe damage produces episodic memory impairment. J Int Neuropsychol Soc 1:525-536.

Wheeler ME, Buckner RL (2003) Functional dissociation among components of remembering: control, perceived oldness, and content. J Neurosci 23:3869-3880.

Worsley KJ, Friston KJ (1995) Analysis of fMRI time-series revisitedagain. NeuroImage 2:173-181.

Yonelinas AP (2002) The nature of recollection and familiarity: a review of 30 years of research. J Memory Language 46:441-517. 